TI 2011-103/3

Tinbergen Institute Discussion Paper

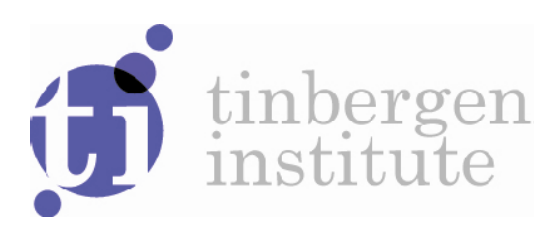

\title{
The Economic Impact of Immigration on the Labor Market of Host Countries - Meta-Analytic Evidence
}

Simonetta Longhi*

Peter Nijkamp*** lacques Poot $* * *$

* Institute for Social and Economic Research, University of Essex, Colchester, United Kingdom;

** Department of Spatial Economics, VU University Amsterdam, The Netherlands;

$* *$ Population Studies Centre, University of Waikato, Hamilton, New Zealand. 
Tinbergen Institute is the graduate school and research institute in economics of Erasmus University Rotterdam, the University of Amsterdam and VU University Amsterdam.

More TI discussion papers can be downloaded at http://www.tinbergen.nl

Tinbergen Institute has two locations:

Tinbergen Institute Amsterdam

Gustav Mahlerplein 117

1082 MS Amsterdam

The Netherlands

Tel.: +31(0)205251600

Tinbergen Institute Rotterdam

Burg. Oudlaan 50

3062 PA Rotterdam

The Netherlands

Tel.: +31(0)10 4088900

Fax: +31(0)104089031

Duisenberg school of finance is a collaboration of the Dutch financial sector and universities, with the ambition to support innovative research and offer top quality academic education in core areas of finance.

DSF research papers can be downloaded at: http://www.dsf.nl/

Duisenberg school of finance

Gustav Mahlerplein 117

1082 MS Amsterdam

The Netherlands

Tel.: +31(0)20 5258579 


\title{
The Economic Impact of Immigration on the Labor Market of Host Countries - Meta-Analytic Evidence
}

Simonetta Longhi ${ }^{*}$, Peter Nijkamp ${ }^{* *}$ and Jacques Poot ${ }^{* * *}$

\begin{abstract}
The number of immigrants across the world has doubled since 1980. The estimates of the impact of immigration on wages and employment in host countries are quantitatively small but vary widely. We use meta-regression analysis to show how the estimates vary with definitions of the labor market, the extent of substitutability of foreign and native workers, and controls for endogeneity of immigrant settlement. On average, the impact on employment of the native born is smaller than on wages, and impacts are generally smaller in the U.S. than in other countries studied to date. From the policy perspective, attention must now focus on distributional and long-run productivity effects.
\end{abstract}

PN309SLJP

\footnotetext{
* Institute for Social and Economic Research, University of Essex, Colchester, United Kingdom E-mail: slonghi@essex.ac.uk

** Department of Spatial Economics, VU University Amsterdam, The Netherlands. Email:pnijkamp@feweb.vu.nl

*** Population Studies Centre, University of Waikato, Hamilton, New Zealand. Email: jpoot@waikato.ac.nz
} 


\section{Introduction}

One of the most significant demographic and socio-economic changes in the world in recent decades has been the growth in the foreign-born population, particularly among developed countries. The demographic, economic, social and fiscal consequences of this population redistribution are of great concern to governments of sending and receiving countries alike; and have provided the impetus of major reviews, including the forthcoming Human Development Report (UNDP, 2009). Since 1980, the estimated foreign-born population of the world doubled to 191 million in 2005 (United Nations, 2006). The number of foreign born in the U.S. increased 2.7 fold from 14 million in 1980 to 38 million in 2005, while in Europe the foreign-born population tripled over this period (see Table 1). In recent years the number of immigrants has undoubtedly exceeded the 200 million mark although the current global economic downturn is causing increasing return migration, particularly of Mexican immigrants from the U.S. and of eastern European immigrants from Western Europe (OECD, 2009; Papademetriou and Terrazas, 2009). However, given global economic integration, low real costs of travel and persistently large differences between countries in terms of economic wellbeing and demographic trends, global recovery from next year onwards is likely to coincide with the foreign-born population in the developed world increasing once again.

Given the phenomenal increase in cross-border migration and mobility, it is not surprising that there has been a burgeoning scientific literature that has attempted to document and quantify ways in which immigrants affect the lives of the populations of host countries. Such impacts are of course wide ranging across cultural, social, economic, environmental and several other domains. Sovereign nations will continue to exercise their right to admit or stop foreigners visiting or residing within their territory (although their control of population is sometimes severely tested by illegal migration). The size and composition of immigration that maximizes the wellbeing of the host population is therefore an important policy question (Hanson, 2008). Opinion surveys have shown that those who consider immigrants as competing with themselves in the labor market are naturally the most reluctant to support greater inflows (Mayda, 2006; Dustmann and Glitz, 2005). It is therefore not surprising that recent job losses in many countries and increasing rates of unemployment are coinciding with increasing resistance to immigration and that 
this is influencing political discourse and policy formulation. However, the sometimes heated public debate is often guided by unverified generalizations. The need for a careful synthesis of the available empirical research on the economic and broader consequences of immigration is greater than ever. Given that the number of publications on this topic is vast, a structured approach to summarize this literature is desirable. One approach that is widely used in the life sciences, but has also gained increasing popularity in economics, is that of meta-analysis: a set of statistical techniques to analyze the distribution of estimated correlations or other statistics used for hypothesis testing (Cooper and Hedges, 1994). In this article we summarize several meta-analyses of estimates of wage and employment effects of immigration.

The focus on the labor market can be easily justified. Attitudes towards immigration are predominantly shaped by perceived consequences for the labor market and the public sector, as well as the extent to which survey respondents experience growing ethnic and cultural diversity as threatening or beneficial (Mayda, 2006; Dustmann and Glitz, 2005). A core concern is the extent to which the host country population may find their labor earnings and employment affected by immigrants. This is one of the most extensively researched issues in the immigration debate. The emphasis in recent years has been on the precise estimation of the effect of immigration on wages of the host population. Much of this research has been conducted with U.S. data, but increasingly evidence is also available from Europe and elsewhere (Longhi et al, 2005). There are fewer estimates of the effect of immigration on employment of the native born population but again these estimates cover a range of developed host countries (Longhi et al, 2008a). Before reporting the available estimates, we first briefly review the commonly used methodologies. 


\section{Exploiting the Geographical Selectivity of Immigrants}

To assess the impact of immigrants on a labor market, researchers have often exploited the fact that new immigrants initially arrive in a relatively small number of local labor markets, reinforcing historical preferences for certain cities, particularly those close to borders or with major international (air)ports. Migrants influence both the supply side and the demand side of the local labor market. ${ }^{1}$ On the supply side, they increase the potential supply of labor while on the demand side they consume goods and services from the day of arrival. Their presence triggers a range of economic effects that will be different in the long run from those in the short run.

In the short run, an increase in the supply of a specific type of labor through immigration will lower its price (i.e. the wage for this type of labor) and firms will expand production of goods and services, and adopt production technologies, that use this labor relatively intensively. Certain output prices may decrease (Lach, 2007). On the other hand, markets where supply is relatively inelastic in the short run, such as rental property, may find prices going up due to the increased demand associated with a larger population (Saiz, 2007). The additional employment and sales in the local economy will yield more tax revenue, but also increase the demand for public services. On balance, the net fiscal impact tends to be positive. The evidence on the fiscal impact is briefly surveyed in Pekkala Kerr and Kerr (2009).

The presence of additional labor supply raises the return to the productive capital of firms. This will trigger additional investment until in the long run the rate of return to capital in the local labor market is back to the national average. The additional investment raises the demand for labor and reverses the labor supply effect of a 'wave' of immigration. Moreover, those native born and earlier immigrants who are the closest substitutes for the new immigrants (i.e. their occupations, skills and experience are similar) may respond to the initial decline in wages by lowering their hours worked, withdrawing from the labor market or moving elsewhere - thereby also dampening the downward wage effect. The relative importance of these various adjustment mechanisms is still not known. For example, the evidence regarding outward migration remains inconclusive, with some studies suggesting that

\footnotetext{
${ }^{1}$ The national labor market is a geographic partitioning of local labor markets defined by the maximum distances people are willing to commute. Such local labor markets operate like small open economies that interact with other local labor markets and the rest of the world.
} 
immigration leads to net inward migration of native born (Card, 2001; Pischke and Velling, 1997) while others estimate net outward migration (Borjas, 2006; Hatton and Tani, 2005).

Broadly speaking, if the open local economy operates at constant returns to scale and immigration has no impact on long-run productivity growth, the economic impact of an immigration wave is merely transitory due to the adjustment mechanisms described above. Prices, wages and rates of return will in the long run be the same as before. The only thing that may change permanently is the composition of output and employment, depending on the substitutability or complementarity of immigrants and local workers.

To quantify these short-run and long-run local effects requires ideally a dynamic multi-regional general equilibrium model that captures the myriad responses of households and firms in this local economy and the spillover effects to the rest of the nation. In practice such research is hampered by the difficulty of often having insufficient data to assign realistic values to a huge number of behavioral parameters.

Therefore, researchers have used observed changes over time and space in specific types of migrants relative to native born workers to infer consequences for wages and employment of the latter, predominantly by multivariate regression models in which the labor market variable of interest (e.g. wages, employment or unemployment of the native born or of earlier immigrants) in the $j^{\text {th }}$ local labor market at time $t\left(y_{j t}\right)$ is modeled as a function of a measure of immigration at that time $\left(m_{j t}\right)$, a vector of co-variates $\mathbf{x}_{j t}$ and random disturbances $\varepsilon_{j t}$.

$$
y_{j t}=\beta m_{j t}+\mathbf{x}_{j t}{ }^{\prime} \boldsymbol{\alpha}+\varepsilon_{j t}
$$

If $y_{j t}$ refers to (the natural logarithm of) wages of workers who are similar to the immigrants in terms of their labor market attributes, we expect $\beta<0$. Since this methodology exploits variation in immigration across local labor markets it is usually referred to as the 'area' approach. However, this methodology leads to upward biased estimates of $\beta$ if immigrants are attracted to regions where wages are relatively high or if immigrants arrive predominantly during buoyant phases of the business cycle.

Three methods have been developed to reduce this bias. The first is to replace the immigration flow $m_{j t}$ by an exogenous instrument that is correlated with it, such as 
the proportion of foreign born in that labor market at some past date. This does not fully resolve the bias problem if past shocks to wages affected past immigration and therefore indirectly current wages. Nonetheless, estimates of a downward effect on wages are somewhat larger when valid instruments are used (Longhi et al, 2005).

The second way to reduce the bias is to focus on the impact of a sudden large and unexpected migration flow such as the Mariel boat lift of Cubans to Miami in 1980 (Card, 1990) or the migration of Russian Jews to Israel after the collapse of the Soviet Union (Friedberg, 2001). This is referred to as the 'natural experiment' approach. Interestingly, such natural experiments tend to reinforce that wage impacts are very small rather than yielding the larger estimates that may be expected when the endogeneity bias is removed.

The third method is to take a national perspective. In this case it is assumed that the inflow at the national level is predominantly determined exogenously by immigration policies. Such policies tend to admit a flow of workers of whom the composition is quite different from that of the native born population, with an overrepresentation of both highly skilled professionals and unskilled workers. This 'factor proportions' approach exploits these relative supply shocks and estimates the extent to which employers adjust their employment of each type of worker as a consequence of immigration, given observed changes in relative wages. Using production theory, the factor proportions approach yields elasticities of substitution between new immigrant workers, natives and earlier immigrants. These substitution elasticities permit a simulation of what a particular national immigration shock would imply for wages of different types of workers in the host population. Substitution elasticities are calculated for groups of workers who are narrowly defined by education and experience. The extent to which immigrants and natives - within narrowly defined skill groups - are close substitutes remains disputed (Ottaviano and Peri, 2008; Borjas, 2009). Nonetheless, it is plausible that labor demand and wages may increase of those native born workers who complement the new immigrants in the expanding sectors, whereas there may be downward pressure on wages of those who directly compete with any newcomers. The strongest evidence of this substitutability is that the largest downward wage effects are observed for earlier immigrants. They are arguably the closest substitutes to newcomers. This is also a robust conclusion from meta-analysis to which we will now turn. 


\section{Meta-analysis of wage and employment effects}

Meta-analysis aims to identify sources of variation in empirical estimates that are broadly comparable. Where units of measurement differ, standardization is naturally a first requirement (for example, by transforming estimates into dimensionless elasticities). Where this is not possible, a more qualitative approach may be adopted in which the comparison is based on the likelihood of rejection of a common hypothesis, given the empirical evidence. Because in economic research more importance is attached to innovativeness rather than replication, the number of directly comparable estimates of a specific quantitative impact is rather small compared with the number of conclusions that have been drawn with respect to statistical significance of an immigration variable in regression models. A trade-off therefore arises in meta-analysis in economics: a focus on the quantitative impact lowers the number of comparable studies but provides the means of deriving a summary value of the economic effect (e.g. an average elasticity). A focus on statistical significance greatly increases the number of studies that can be compared, but the summary of evidence may provide a precise statement only with respect to the presence of statistical association, but not regarding the magnitude of that association. Combining previously published meta-analyses (Longhi et al, 2005; Longhi et al, 2008a; Longhi et al, 2008b), we make use here of both approaches and show that the results - in terms of the average impact and the role of various study characteristics are broadly consistent across the two.

The meta-analyses are summarized in Table 2. Pooling 344 estimates reported in 18 studies published between 1982 and 2003, the simple average of the wage impact of a 1 percentage point increase in the proportion of foreign born in the population is a decline in wages of about $0.12 \%$. However, the range of estimates is very wide, running from $-5.4 \%$ to $+4.5 \%$. Moreover, the calculation of an ordinary average is not the best summary measure available. Individual estimates would need to be weighted in terms of differences in precision, correlations between estimates derived from the same study, and various aspects of study quality. A weighted least squares (WLS) regression allows us to assess the links between the observed effects and various study characteristics. The notes at the bottom of Table 2 provide details of how the regression models have been calculated. Using the regression model, the 
predicted average percentage decline in weekly wages following a 1 percentage point increase in the share of foreign born is $-0.21 \%$ for native born workers in the U.S. and $-1.61 \%$ in Europe. ${ }^{2}$ Immigrants clearly have a somewhat larger downward impact on wages in Europe than in the U.S., despite wage flexibility in the latter country being generally greater. However, the wage impact is numerically very small everywhere. For example, even in a European country in which the migrant share of the population is as high as 15 percent, growth of the number of immigrants by another 10 percent which is numerically a large influx and undoubtedly very visible - would lower wages on average by no more than 2 percent.

A similar meta-regression is reported with respect to employment effects. Across 165 estimates derived from nine studies, the simple average employment effect is a decline in employment of the host population of $-0.24 \%$, following a 1 percentage point increase in the share of foreign born in the population, but with a range from $-3.9 \%$ to $+6.2 \%$. WLS can again be used to provide a weighted estimate that takes account of differences in quality, precision and study design. Using the WLS regression model reported in Table 2, the predicted average percentage decline in employment of natives following a 1 percentage point increase in the share of foreign born is at the mean level of study characteristics $+0.03 \%$ for the native born in the U.S. and $-0.06 \%$ in countries other than the U.S. (Longhi et al, 2008b). The employment effects are very small. This is plausible given the previous calculated small wage effect and the fact that the wage elasticity of labor supply tends to be very small (Borjas 2010). In the U.S. there appears to be a small net job creation effect, while in the European labor markets there is some net 'crowding out'.

It may be argued that the 18 and nine studies on wage and employment effects respectively that were used to derive the meta-estimates above are not representative of all studies on the labor market impact of immigration that have been conducted to date. One problem is that the units of measurement and the specifications of the regression models are not directly comparable across the full range of available

\footnotetext{
${ }^{2}$ These estimates are predictions from the WLS regression model in which all dummy variables have been set to zero except Large Areas; Areas and Occupation/Skills and Both Genders; and the EU dummy for the prediction of the EU estimate. Hence the estimates refer to those that may be expected when the primary analysis is conducted with data on low skill native men and women who are geographically assigned to large areas in which the labor market is disaggregated by occupation/skills, in which the variables are expressed in first differences and instrumental variables has been used to control for endogeneity of immigration.
} 
studies. ${ }^{3}$ To tackle this problem, we can alternatively consider the available evidence regarding the sign and statistical significance of the relationship between immigration and labor market outcomes. This choice allows the comparison of the results of a much larger number of studies. The findings by Longhi et al (2008b) will be presented here in a concise way. Considering 853 regressions of the impact of immigration on wages and 495 on the impact on employment from 36 and 20 studies respectively, we find an average $t$ statistic for the effect of immigration on wages of 0.39 , with a range from -76.7 to +14.7 . With respect to the employment impact, Longhi et al (2008b) find an average $t$ statistic of -0.45 , with a range from -9.4 to +42.0. Naturally, for a given 'true' effect, these $t$ statistics will be positively related to the sample sizes of the underlying primary studies. The distributions indicate that at the $5 \%$ significance level, only $26.8 \%$ of wage regressions in previous studies find a statistically significant negative effect of immigration on wages, while a very similar $26.0 \%$ percent of employment regressions suggest a statistically significant negative effect of immigration on the employment of the native born. The wage and employment effects are not only small, but also hard to estimate with desirable precision. Nonetheless, the variation in study conclusions with respect to the statistical significance of the estimated effect can be investigated by means of an ordered probit model. The results of the ordered probit estimation are also reported in Table 2. Not surprisingly, this model predicts for both wage and employment impacts a statistically insignificant effect at the average of study characteristics.

Generally we would expect studies focusing on small geographic areas to be less likely to detect a negative wage or employment effect due to the adjustment processes that we already alluded to, such as the inward flow of capital, out-migration of the native born, changes in production techniques and changes in the composition of output and trade. The ordered probit model of the measured impact on wages shows that elasticities that are computed using geographically larger definitions of the labor market are more likely to find statistically significant negative $t$ statistics (Table 2 ). With respect to the magnitude of the wage impact, estimation on large areas

\footnotetext{
${ }^{3}$ Another problem is that there can be a selection bias resulting from restricting sampled regressions to those in the English language that are obtainable in printed form or electronically. Unreported estimates are disproportionally those that yield statistically insignificant results. Various methodologies are available to correct for publication bias, see e.g. Stanley 2005. This bias did not turn out to be important in the present context (Longhi et al, 2005; Longhi et al, 2008a; Longhi et al, 2008b).
} 
coincided with a somewhat less negative coefficient, although slightly changed WLS specifications, not reported in Table 2, yielded a greater downward effect on wages in geographically larger areas as well (Longhi et al, 2005). In regressions on employment effects, the size of the labor market area does not affect the conclusions.

The impact of immigration on wages and employment is larger in magnitude when estimated for European and 'other countries' (such as Israel and Australia) rather than for the U.S., although with respect to statistical significance of the results this difference is less clear and applies to the wage impact in 'other countries' only. A lesser impact in the U.S. is plausible given its relatively high level of geographical labor mobility and the relatively greater flexibility and competitiveness of the U.S. labor market.

The greater the level of disaggregation of the labor market data by skill level, the more likely it is that a downward effect on wages and employment is detected. Table 2 shows that studies that define local labor markets by a combination of geography and occupations or skills lead to the estimation of greater negative impacts on employment and wages than studies defining labor markets in geographical terms only.

We noted earlier that instrumental variables are needed in the case of endogeneity of immigration, because the impact is otherwise likely to be biased upwards. In most past studies the instrument chosen is the migrant stock in the previous (data) period under the assumption that immigrants' geographical distribution may depend more on historical trends than current economic conditions. The indication that this may not be a good instrument follows from the fact that using instrumental variables does not make the coefficient of net immigration in wage regressions more negative. However, not using IV estimation biases the impact on employment upward by about 1 percentage point.

It is widely recognized that factor price equalization and region-specific unobserved characteristics might influence immigrant density and/or natives' outcomes, thus possibly generating an underestimation of the impact of immigration when this is computed on cross-sectional data. First-differencing the data may help to correctly capture the short-run effects of immigration (Altonji and Card, 1991). Studies using first-differenced rather than cross-sectional data find indeed a larger negative impact of immigration. 
The political debate on the economic impact of immigration is partly fuelled by the assumption that immigrants are close substitute for natives and, as predicted by the neoclassical model in economics, are bound to generate negative externalities in terms of labor market opportunities of residents. Even when the local labor market is econometrically well defined, the issue of the extent to which immigrants are substitutes or complements to natives, earlier immigrants with the same ethnicity, or immigrants of other ethnicities still remains. A low degree of substitutability between natives and immigrants might explain why the literature has failed to find a large negative wage and employment impact of immigration.

If women's labor force participation is more wage elastic than that of men (the wage elasticity of labor supply of the latter may in fact be negative), the estimated impact of immigration might differ by gender. Furthermore, it has been suggested that immigrants might be substitutes for low-skill natives and for females, but complement highly skilled natives (Borjas, 2003). However, Table 2 shows that the pooling of previous studies by means of meta-regression analysis does not detect a statistically significant difference in wage and employment effects by gender.

The earliest studies assumed perfect substitution between immigrants and natives of any skill level (Grossman, 1982). The immigrant population has on average much lower levels of education than the native population in many countries for which the research has been conducted. ${ }^{4}$ In that case, immigrants are likely to be substitutes for low-skill natives, but complements for high-skill natives. A number of studies estimated the impact of the overall share of immigrants on labor market outcomes of low-skill natives and find a proportionally larger impact of immigration that, however, applies only to a smaller proportion of natives, i.e. those with low skills (Altonji and Card, 1991; Winter-Ebmer and Zweimuller, 1996; Johannsson and Weiler, 2004). More recent studies partly relax the assumption of perfect substitutability and disaggregate both immigrants and natives by skill although in most cases regressions are still computed including all observations so that the results only inform on the average elasticity across skill groups (Dustmann et al, 2005; Card, 2005). Aggregating skills groups did not affect the estimated wage impact across the sample of studies, but it did make the impact on employment of the native born 0.88

\footnotetext{
${ }^{4}$ This is not the case in countries that select immigrants strongly on the basis of skills, such as Australia, Canada and New Zealand.
} 
percentage points more negative. It also made wage and employment effects more statistically significant.

A robust conclusion of the literature is that new immigrants have a larger impact on wages of earlier immigrants rather than on the wages of the native born. In Table 2 this is shown by the statistically significant negative coefficient of immigrants under the 'affected birthplace group' and the impact being less negative when natives and immigrants are combined (with regressions on the impact on natives being the reference category).

\section{Remaining questions}

Research on the impact of immigrants on economic outcomes for the native born population has intensified tremendously in recent years and covers many parts of the world. Our meta-analysis reinforces the robustness of the conclusion that the average wage and employment impact is small. However, even where the average impact is small, the distributional impacts may be larger and will depend on the skill mix of the immigrant inflow vis-à-vis that of the host labor force, the change in the composition of demand, and the change in non-wage income. These distributional impacts will also change over time.

Consequently, there is still a vast research agenda ahead of us. First, it would be particularly useful to identify whether the consequences vary with the 'drivers' of the inward flows, such as changes in admission criteria, but also with the nature of push factors (war, famine, opportunity-seeking) or with the type of the migration itself (temporary or permanent). Secondly, there is an equally fast growing literature on the economic integration into the host economy (for a recent U.S. review, see for example Duleep and Dowhan, 2008), but the extent to which the integration process (by length of stay in the host country, skill, age, gender, employment status, cultural-ethnic networks, etc.) influences the immigrants' impact on the host labor market and society more generally, remains remarkably under-researched. A distinction between firstand second-generation migrants would be highly desirable as well.

What is additionally still missing from the literature is an understanding of the impact of immigration on the drivers of economic development such as innovation, investments in education and training, scale effects, and the diversity of cities. Even if there is a downward effects on wages and employment of the native born in the short- 
run, small dynamic benefits may more than compensate for that in the long-run. This brings us to a last caveat of the existing literature, viz. the impact of the limited time horizon adopted in many of the modeling studies undertaken world-wide. Clearly, in the short run and under static conditions, migration movements may generate various crowding-out or congestion effects, but in the long run various positive generative effects may be expected. Virtually all countries are now affected by cross-border migration, as senders or recipients of migrants, or in many cases both. Careful comparative migration impact assessment may then be helpful to avoid unverified prejudices.

\section{References}

Altonji, J.G. and Card, D. (1991) The Effect of Immigration on the Labor Market Outcomes of Less-Skilled Natives. Immigration, Trade and the Labor Market. Ed. by Abowd, J.M. and Freeman, R.B., NBER: 201-234.

Borjas, G.J. (2003) The Labor Demand Curve Is Downward Sloping: Reexamining the Impact of Immigration on the Labor Market. Quarterly Journal of Economics 118(4): 1335-1374.

Borjas, G.J. (2006) Native Internal Migration and the Labor Market Impact of Immigration. The Journal of Human Resources 41(2): 221-258.

Borjas, G.J. (2009) The Analytics of the Wage Effect of Immigration, NBER Working Paper 14796.

Borjas, G.J. (2010) Labor Economics (5th Ed.), McGraw-Hill Irwin.

Card, D. (1990) The Impact of the Mariel Boatlift on the Miami Labor Market. Industrial and Labor Relations Review 43(2): 245-257.

Card, D. (2001) Immigrant Inflows, Native Outflows, and the Local Market Impacts of Higher Immigration. Journal of Labor Economics 19(1): 22-64.

Card, D. (2005) Is the New Immigration Really So Bad? The Economic Journal 115(507): F300-F323.

Cooper, H. and Hedges, L.V., Eds. (1994) The Handbook of Research Synthesis. New York, Russel Sage Fundation.

Duleep, H.O. and Dowhan, D.J. (2008) Research on Immigrant Earnings. Social Security Bulletin 68(1): 31-50.

Dustmann, C. and Glitz, A. (2005) Immigration, Jobs and Wages: Theory Evidence and Opinion. London, Centre for Research and Analysis of Migration.

Dustmann, C., Hatton, T. and Preston, I. (2005) The Labour Market Effects of Immigration. The Economic Journal 115(507): F297-F299.

Friedberg, R.M. (2001) The Impact of Mass Migration on the Israeli Labor Market. The Quarterly Journal of Economics 116(4): 1373-1408.

Grossman, J.B. (1982) The Substitutability of Natives and Immigrants in Production. The Review of Economics and Statistics 64(4): 596-603.

Hanson, G.H. (2008) The Economic Consequences of the International Migration of Labor, NBER Working Paper 14490.

Hatton, T.J. and Tani, M. (2005) Immigration and Inter-Regional Mobility in the UK, 1982-2000. The Economic Journal 115(507): F342-F358. 
Johannsson, H. and Weiler, S. (2004) Local Labor Market Adjustment to Immigration: The Roles of Participation and the Short Run. Growth and Change 35(1): 61-76.

Lach, S. (2007) Immigration and Prices. Journal of Political Economy 115(4): 548587.

Longhi, S., Nijkamp, P. and Poot, J. (2005) A Meta-Analytic Assessment of the Effect of Immigration on Wages. Journal of Economic Surveys 19(3): 451-477.

Longhi, S., Nijkamp, P. and Poot, J. (2008a) The Impact of Immigration on the Employment of Natives in Regional Labour Markets: A Meta-Analysis. Migration and Human Capital. Ed. by Poot, J., Waldorf, B. and van Wissen, L. Cheltenham (UK), Edward Elgar: 173-193.

Longhi, S., Nijkamp, P. and Poot, J. (2008b) Meta-Analysis of Empirical Evidence on the Labour Market Impact of Immigration. Région et Développement 27(1): 161-191.

Mayda, A.M. (2006) Who Is against Immigration? A Cross-Country Investigation of Individual Attitudes toward Immigrants. Review of Economics and Statistics 88(3): 510-530.

OECD (2009) International Migration Outlook - Special Focus: Managing Labour Migration Beyond the Crisis, OECD, Paris.

Ottaviano, G.I.P. and Peri, G. (2008) Immigration and National Wages: Clarifying the Theory and Empirics, NBER Working Paper 14188.

Papademetriou, D.G. and Terrazas, A. (2009) Immigrants and the Current Economic, Migration Policy Institute, Washington DC.

Pekkala Kerr, S. and Kerr, W. (2009) Economic Impacts of Immigration: A Survey, Harvard Business School Working paper 09-013.

Pischke, J.-S. and Velling, J. (1997) Employment Effects of Immigration to Germany: An Analysis Based on Local Labor Markets. The Review of Economics and Statistics 79: 594-604.

Saiz, A. (2007) Immigration and Housing Rents in American Cities. Journal of Urban Economics 61(2): 345-371.

Stanley, T.D. (2005) Beyond Publication Bias. Journal of Economic Surveys 19(3): 309-345.

Sutton, A.J., Abrams, K.R., Jones, D.R., Sheldon, T.A. and Song, F. (2000) Methods for Meta-Analysis in Medical Research. New York, John Wiley and Sons.

UNDP (2009) Human Development on the Move. New York: United Nations Development Programme (forthcoming).

United Nations (2006) World Migrant Stock, the 2005 Revision, UN Department of Economic and Social Affairs, New York.

Winter-Ebmer, R. and Zweimuller, J. (1996) Immigration and the Earnings of Young Native Workers. Oxford Economic Papers 48(3): 473-491. 
Table 1. Growth in the foreign born population by world region, 1980-2005

\begin{tabular}{|c|c|c|c|}
\hline & $\begin{array}{c}\mathbf{1 9 8 0} \\
\text { (million) }\end{array}$ & $\begin{array}{c}\mathbf{2 0 0 5} \\
\text { (million) }\end{array}$ & $\begin{array}{c}\text { Average } \\
\text { annual \% change }\end{array}$ \\
\hline Africa & 14,096 & 17,069 & 0.77 \\
\hline Asia & 32,114 & 53,291 & 2.05 \\
\hline Europe & 21,894 & 64,116 & 4.39 \\
\hline North America & 18,087 & 44,493 & 3.67 \\
\hline Latin America and Caribbean & 6,079 & 6,630 & 0.35 \\
\hline Oceania & 3,755 & 5,034 & 1.18 \\
\hline World & 99,276 & 190,633 & 2.64 \\
\hline
\end{tabular}

Source: (United Nations, 2006). 
Table 2. Multivariate analysis of the relationship between study features and labor market impacts of immigration

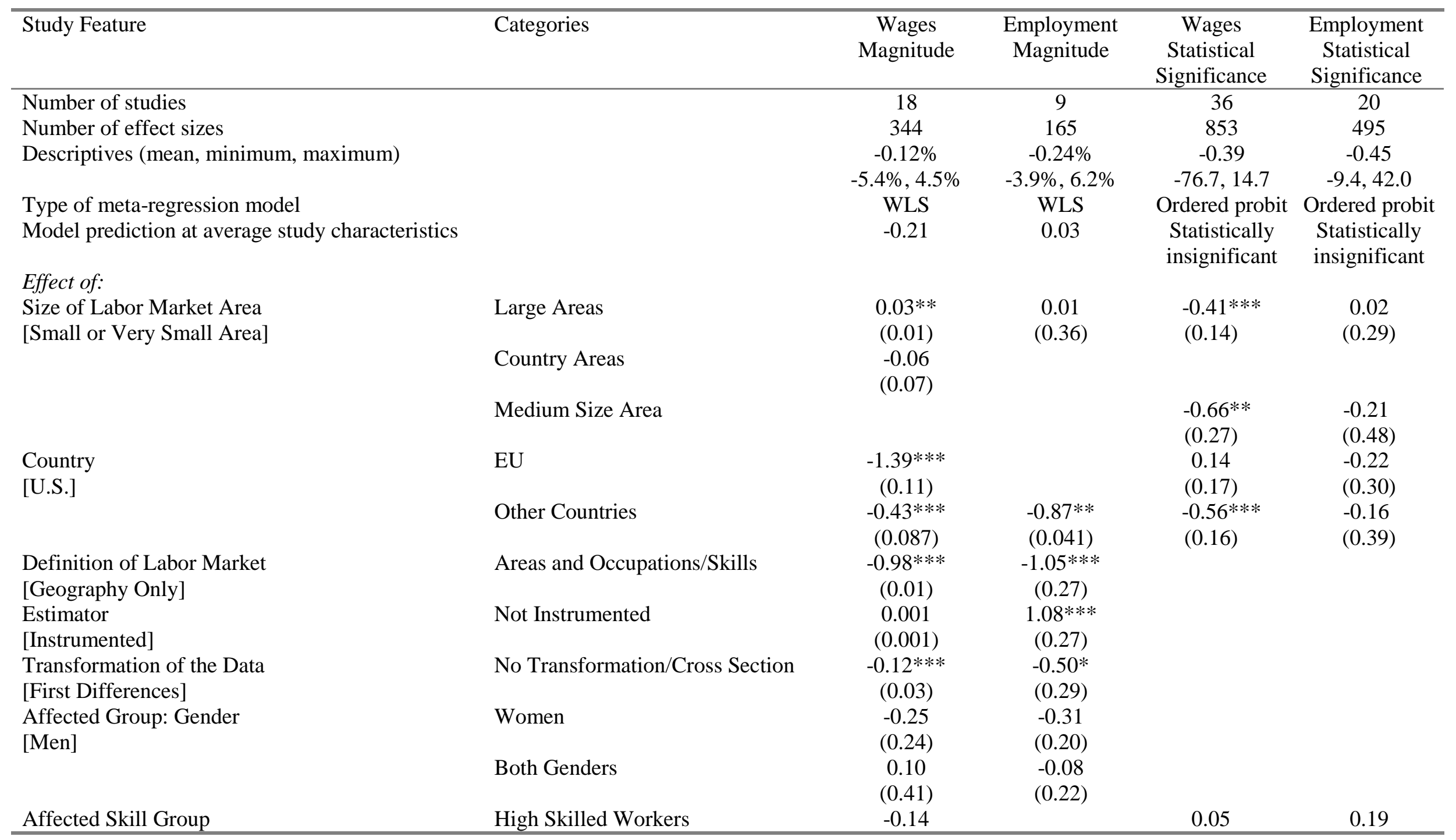




\begin{tabular}{|c|c|c|c|c|c|}
\hline [Low Skilled Workers] & & $(0.30)$ & & $(0.12)$ & $(0.19)$ \\
\hline \multirow{2}{*}{$\begin{array}{l}\text { Affected Birthplace Group } \\
\text { [Natives] }\end{array}$} & Earlier Immigrants & $-0.003 * * *$ & -0.31 & $-0.32 * *$ & -0.07 \\
\hline & & $(0.001)$ & $(0.34)$ & $(0.15)$ & $(0.20)$ \\
\hline
\end{tabular}

Notes: Robust standard errors in parentheses; * significant at 10\%; ** significant at 5\%; *** significant at 1\%; Reference categories in brackets.

Wages Magnitude: WLS weighted by the inverse standard error of the effect sizes. The variance-covariance matrix of the WLS estimations has been computed following (Sutton et al. 2000). Other explanatory variables: immigrants' skills: high skills, all skills, [low skill]; international trade: accounted for, [not Accounted for]; approach: factor proportion approach, [area approach]; definition of immigrants: recent immigrants, ethnicity, [other]; definition of wages: annual, monthly, daily, hourly, no details, [weekly]; intercept. Source: (Longhi et al, 2005). The Model Prediction has been computed setting all dummies to zero except 'large areas'; 'areas and occupation/skills'; and 'both genders'.

Employment Magnitude: WLS weighted by the square root of the sample size on which the employment elasticities are computed. Other explanatory variables: weights: no, [yes]; publication bias: standard error of the effect size; intercept. Source: (Longhi et al, 2008a). The Model Prediction has been computed setting all dummies to zero except 'large areas', 'areas and occupation/skills', and 'both genders'.

Wages and Employment Statistical Significance: Coefficients of an ordered probit model. Other explanatory variables: type of publication: book, working paper, [journal]; year of publication: 1990s, 2000s, [1980s]; approach: factor proportion approach, natural experiment, [area approach]; kind of data: pooled cross section and time series, [cross section]; length of data in years; natural logarithm of sample size). Source: (Longhi et al, 2008b). 